\title{
ACCUMULATION OF PHOSPHATIDYLSERINE IN STRICTLY ANAEROBIC LACTATE FERMENTING BACTERIA
}

\author{
L. M. G. VAN GOLDE, J. AKKERMANS-KRUYSWIJK, W. FRANKLIN-KLEIN, \\ A. LANKHORST and R. A. PRINS \\ Laboratory of Veterinary Biochemistry, State University of Utrecht, Biltstraat 172, Utrecht, The Netherlands
}

Received 29 January 1975

Revised version received 27 February 1975

\section{Introduction}

Phosphatidylserine has been found as a minor phospholipid constituent in most bacteria investigated so far [1-4]. Recently we demonstrated [5] that this phospholipid is a major membrane component of Megasphaera elsdenii, a strictly anaerobic rumen bacterium. Both phosphatidylserine and phosphatidylethanolamine, the only other major phospholipid present in this organism, were found to comprise high levels of plasmalogen analogues. A limited search among other predominant rumen bacteria, such as Ruminococcus albus, R. falvefaciens, Bacteroides succinogenes, B. amylophilus, Eubacterium cellulosolvens, E. ruminantium and Methanobacterium ruminantium showed that these organisms contain only trace amounts (less than $1 \%$ ) of phosphatidylserine (unpublished results). Also from the extensive studies of Rizza et al. [6] and Lev and Milford [7] on the lipids of Bacteroides melaninogenicus, of Kunsman [8] on Bacteroides ruminicola and of Makula and Finnerty [9] on Desulphovibrio species, it is clear that the unique simple polar lipid composition of $M$. elsdenii is not a general characteristic of anaerobic rumen or intestinal bacteria. One of the major functions of $M$. elsdenii is the fermentation of lactate produced by other microorganisms in the rumen [10]. It was thought of interest to investigate whether the uncommon accumulation of phosphatidylserine in $M$. elsdenii may be related to the capability of this organism to ferment lactate. In this paper we report that three other strictly anaerobic bacteria which are known to ferment lactate, also accumulate phosphatidylserine.

\section{Materials and methods}

\subsection{Baterial strains and culture conditions}

Megasphaera elsdenii B 159 (ATCC 17752) was generously provided by Dr M. P. Bryant (University of Illinois, Urbana, USA) and Anaerovibrio lipolytica $5 \mathrm{~S}$ by Dr. C. Henderson (Rowett Research, Aberdeen, Great Britain). Veillonella parvula (ATCC 10790) and Selenomonas ruminantium var. lactilytica (ATCC 19205) were obtained from the American Type Culture Collection (Rockville, Maryland, USA). The compostition of the medium for growth of $M$. elsdenii has been described in detail previously [5] . V. parvula, $A$. lipolytica and $S$. ruminantium were grown in a medium containing (in $\mathrm{g} / 1$ ): trypticase (BBL), 5; yeast extract (OXOID), $5 ; \mathrm{KH}_{2} \mathrm{PO}_{4}, 0.75 ; \mathrm{K}_{2} \mathrm{HPO}_{4}$, $0.75 ; \mathrm{NaCl}, 1.50 ;\left(\mathrm{NH}_{4}\right)_{2} \mathrm{SO}_{4}, 0.75 ; \mathrm{CaCl}_{2} \cdot 2 \mathrm{H}_{2} \mathrm{O}$, $0.15 ; \mathrm{MgSO}_{4} \cdot 7 \mathrm{H}_{2} \mathrm{O}, 0.15$; resazurin, 0.001 ; cysteine. $\mathrm{HCl}, 0.3$ and $\mathrm{NaHCO}_{3}, 5$. DL-lactate, glycerol and mannitol (5-10 $\mathrm{mM})$, respectively, were used as substrates for these organisms. Large cultures of the various organisms were grown in 1 litre-serum flasks fitted with aluminum screw caps and rubber inlayseals. The medium was autoclaved in the flasks and cooled under a stream of oxygen-free sterile $\mathrm{CO}_{2}$. Bicarbonate, cysteine. $\mathrm{HCl}$ and substrate (autoclaved separately) were then added aseptically just prior to inoculation. The cells were harvested by 
centrifugation in the GSA-rotor of the Sorvall RC-2B centrifuge for $20 \mathrm{~min}$ at $16000 \mathrm{~g}$.

\subsection{Growth of the various organisms in the presence of labelled compounds}

Ten $\mathrm{ml}$ cultures of the organisms were grown until an $\mathrm{A}$ absorbance of 0.15 was reached. At this point $100 \mu \mathrm{Ci}$ of ${ }^{32} \mathrm{P}_{\mathrm{i}}$ or $10 \mu \mathrm{Ci}$ of $\left[1-{ }^{14} \mathrm{C}\right]$ - or $\left[3-{ }^{14} \mathrm{C}\right]$ serine were added after which growth was continued until the late logarithmic phase $(A 0.9)$. The cells were then collected by filtration through Gelman Metrical Alpha-6 filters (pore size $0.45 \mu \mathrm{m}$ ). The cell pellets were immediately taken up in $4 \mathrm{ml}$ of methanol and the lipids extracted as described in detail by Van Golde et al. [11].

\subsection{Chromatographic procedures}

The diacylphospholipids and their plasmalogen derivatives were separated via two-dimensional silica thin-layer chromatography. Prior to development in the second direction and alk-1-enyl chains of the plasmalogens were released by treatment with a $12 \%$ (v/v) solution of conc. $\mathrm{HCl}$ in methanol [12]. The details of this procedure have been reported previously [5]. The diacylphospholipids and the monoacylphospholipids derived from the plasmalogens originally present were detected by staining with iodine or, in case of experiments with labelled precursors, by autoradiography and radiochromatogram scanning [5]. The diacylphospholipids and plasmalogen derivatives were then scraped from the plates for phosphorus determination [13] or for assay of radioactivity by means of liquid scintillation counting [5]. Mild alkaline hydrolysis of the diacylphospholipids was carried out via the method of Dawson [14] as modified by Chang and Kennedy [15]. Separation and identification of the various glycerophosphoryldiesters was accomplished by paperchromatography as described in details previously [5] .

\section{Results}

In table 1 the phospholipid composition of $M$. elsdenii is compared with that of three other representatives of the small group of strictly anaerobic bacteria which possess the capability to ferment lactate: Anaerovibrio lipolytica [16], Veillonella parvula [17-19] and Selenomonas ruminantium var. lactilytica $[10]$. The identity of the various phospholipid constituents of these organisms was established by the following criteria: 1) After growth in the presence of ${ }^{32} P_{i}$ the labelled phospholipids cochromatographed on two-dimensional thin-layer plates with known standards of phosphatidylserine, phosphatidylethanolamine and their plasmalogen analogues. 2) Mild alkaline hydrolysis followed by separation of the resultant glycerophosphorodiesters on paper chromatograms [5] yielded two phosphorusand ninhydrinpositive spots co-chromatographing with standards sn-glycero-3-phosphorylserine and -ethanolamine, respectively. 3) After growth of the organisms in the presence of $\left[1-{ }^{14} \mathrm{C}\right]$ serine the phospholipid which co-chromatographed with standard

Table 1

Phospholipid composition of some strictly anaerobic bacteria which share the capability to ferment lactate

\begin{tabular}{llllr}
\hline & $\begin{array}{l}\text { Megasphaera } \\
\text { elsdenii }\end{array}$ & $\begin{array}{l}\text { Veillonella } \\
\text { parvula }\end{array}$ & $\begin{array}{l}\text { Selenomonas } \\
\text { ruminantium } \\
\text { var } \\
\text { lactilytica }\end{array}$ & $\begin{array}{l}\text { Anaerovibrio } \\
\text { lipolytica }\end{array}$ \\
\hline Diacyl phosphatidylserine & 10.0 & 19.0 & 17.6 & 19.8 \\
Serine plasmalogen & 25.8 & 7.5 & 6.6 & 3.5 \\
Diacylphosphatidylethanolamine & 7.8 & 28.5 & 27.2 & 44.8 \\
Ethanolamine plasmalogen & 54.3 & 45.1 & 45.0 & 29.8 \\
Unknown diacylphospholipid & 2.0 & trace & 3.6 & 2.1 \\
\hline
\end{tabular}

Results are expressed as percent of total lipid phosphate 
phosphatidylserine was labelled. The compound which cochromatographed with phosphatidylethanolamine was not labelled as could be expected since this phospholipid is formed by decarboxylation of phosphatidylserine which results in loss of the label [20] . 4) Both phosphatidylserine and -ethanolamine were labelled by growth in the presence of $\left[3 \cdot{ }^{14} \mathrm{C}\right]$ serine. 5) The compound preliminarily identified as phosphatidylserine could be converted into phosphatidylethanolamine by treatment with phosphatidylserine decarboxylase from Escherichia coli [21]. These observations unambiguously demonstrate that phosphatidylserine and phosphatidylethanolamine are the predominant phospholipids in these organisms. In addition to these two major phospholipids a small amount of an unknown diacyl phospholipid, which was minhydrin negative, could be detected in all four organisms (table 1). High levels of plasmalogen analogues, especially of phosphatidylethanolamine, have been reported for anaerobic bacteria, including $M$. elsdenii and $S$. ruminantium [22]. The present study shows that also $A$. lipolytica and $V$. parvula contain ethanolamine plasmalogen as a major lipid constituent. Furthermore, serine plasmalogen could be identified in all four organisms (table 1 ), though abundant amounts of this lipid were found in M. elsdenii, only. Kim et al. [23] and Kamio et al. [24] found significant amounts of alkylether phospholipids (3\% of the total phospholipid content) in $S$.

ruminantium. Though in the present study no detailed investigation on the presence of alkylether phospholipids was carried out, it was found that the aliphatic side-chains of the phospholipids of $M$. elsdenii, $A$. lipolytica and $V$. parvula could be completely removed by the selective acid and alkaline hydrolysis procedure described by Dittmer and Wells [25]. Nevertheless, the occurrence of trace amounts of alkylether phospholipids in these organisms cannot be ruled out completely. In this light it is relevant to mention that Kim et al. also describe a variety of strict anaerobes in which alkylether phospholipids cannot be detected or occur in extremely small quantities [23].

\section{Discussion}

It is clear from the results presented in table 1 that the accumulation of phosphatidylserine is not confined to $M$. elsdenii. Also the other three lactatefermenting strict anaerobes contain significant amounts of this phospholipid. Actually, the content of diacylphosphatidylserine is higher in V. parvula, $A$. lipolytica and $S$. ruminantium than in $M$. elsdenii. In this organism, however, also the plasmalogen analogue of phosphatidylserine accumulates. Since phosphatidylserine normally does not accumulate in aerobic nor in anaerobic bacteria, the results in this paper suggest that the abundance of serine containing lipids in M. elsdenii, A. lipolytica, V. parvula and $S$. ruminantium may be correlated with the capability of these organisms to ferment or to take up lactate. However, lactate fermentation is not the only common property of these four organisms: they also belong to the small group of strictly anaerobic bacteria which are capable of fermenting at least some amino acids [10,16-19]. Furthermore, they all produce propionate during fermentation. In this respect it is noteworthy that one of the major fatty acids found in the lipids of these four organisms is $C_{17: 1}$ (unpublished results), an acid which is rather uncommon for bacteria and which is probably synthesized from propionate. Further experiments to decide which of these alternative common factors or combination of factors is correlated with the abundance of phosphatidylserine in the membranes of these organisms, are currently under investigation.

\section{Acknowledgement}

The present investigations have been carried out under the auspices of the Netherlands Organization for Chemical Research (S.O.N.) and with financial aid from the Netherlands Organization for the Advancement of Pure Research (Z.W.O.).

\section{References}

[1] Op den Kamp, J. A. F., van Deenen, L. L. M. and Tomasi, V. (1969) in: Structural and Functional Aspects of Lipoproteins in Living Systems (Tria, E. and Scanu, A. M., eds.) pp. 227-325, Academic Press, London

[2] Kates, M. and Wassef, M. K. (1970) Annu. Rev. Biochem. $39,323-359$.

[3] Lennarz, W. J. (1970) Annu. Rev. Biochem. 39, 359-389. 
[4] Van den Bosch, H., van Golde, L. M. G. and van Deenen, L. L. M. (1970) Rev. of Physiol. 66, 13-147.

[5] Van Golde, L. M. G., Prins, R. A., Franklin-Klein, W. and Akkermans-Kruyswijk, J. (1973) Biochim. Biophys. Acta 326, 314-323.

[6] Rizza, V., Tucker, A. N. and White, D. C. (1970) J. Bact. 101, 84-91.

[7] Lev. M. and Milford, A. F. (1972) J. Lipid Res. 13, $364-370$.

[8] Kunsman, J. E. (1973) J. Bact. 113, 1121-1126.

[9] Makula, R. A. and Finnerty, W. R. (1974) J. Bact. 120, 1279-1283.

[10] Hungate, R. E. (1966) The Rumen and its Microbes, pp. 76-77, Academic Press, New York.

[11] Van Golde, L. M. G., Schulman, H. and Kennedy, E. P. (1973) Proc. Natl. Acad. Sci. U.S. 70, 1368-1372.

[12] Singh, H., Spritz, N. and Geyer, B. (1971) J. Lipid Res. $12,473-481$.

[13] Bartlett, G. R. (1959) J. Biol. Chem. 234, 466-468.

[14] Dawson, R. M. C. (1954) Biochim. Biophys. Acta. $14,374-379$.
[15] Chang, Y. and Kennedy, E. P. (1967) J. Biol. Chem. 242, 516-519.

[16] Prins, R. A., Lankhorst, A., van der Meer, P. and van Nevel, C. J. (1975) Antonie van Leeuwenhoek, in press.

[17] Rogosa, M. (1964) J. Bact. 87, 162-170.

[18] Rogosa, M. (1971) Int. J. Syst. Bacteriol. 21, $231-233$.

[19] Ng, S. K. G. and Hamilton, I. R. (1971) J. Bact. 105, 999-1005.

[20] Kanfer, J. and Kennedy, E. P. (1964) J. Biol. Chem. 239, 1720-1726.

[21] Raetz, C. H. R. and Kennedy, E. P. (1972) J. Biol. Chem. 247, 2008-2014.

[22] Kamio, Y., Kanegasaki, S. and Takahashi, H. (1969) J. Gen. Appl. Microbiol. 15, 439-451.

[23] Kim, K. C., Kamio, Y. and Takahashi, H. (1970) J. Gen. Appl. Microbiol. 16, 321-325.

[24] Kamio, Y., Kim, K. C.. and Takahashi, H. (1970) J. Gen. Appl. Microbiol. 16, 291-300.

[25] Dittmer, J. C. and Wells, M. A. (1969) in Methods of Enzy mology (Lowenstein, J. M. ed.) Vol. XIV, pp. 483-530, Academic Press, New York. 